\title{
Development of Web-Based Instruction with Collaborative Learning Model Technique STAD is Applied for Computer Educational Program in Master Degree. Faculty of Education, Naresuan University
}

\author{
Assoc. Prof. Passkorn Roungroung
}

Naresuan University Phisanulok Thailand. ccpasskn@hotmaail.com

Doi:10.5901/mjss.2013.v4n11p542

\begin{abstract}
The primary purpose of this study was aimed 1) to examine the application of Collaborative Learning STAD techniques in the Applied Computer Programming for Education course and 2) to investigate the efficiency and achievement of the Collaborative Learning STAD. The samples included fifty-seven (26 female and 31 male) Master students in Computer Education Program, enrolled in the semester 1/2011. Methodologically, ADDIE Model was employed. The results showed that Collaborative Learning STAD with teaching materials and Web-Based Instruction appeared statistically significant at 0.05 and the efficiency of teaching materials and Web-Based Instruction was of 90.16 and 92.76, respectively and student's opinion was many levels of satisfaction.
\end{abstract}

Keyword: WBI Web based Instruction, CL Collaborative Learning, STAD techniques, media and activity on internet.

\section{Issues and Significance}

The outcomes of the pedagogical arrangement for the Applied Computer Programming for Education course in the semester 1/2010 [1] indicated the vast differences among the students in the classroom, especially learning and practicing on programming which the extent of the student's interest varied greatly. The results also showed that students with higher scores on computer-related courses were more likely interested in learning and practicing, resulted that classroom arrangement didn't meet the expectation of the instructor and student's academic results didn't meet the target goal.

Methodologically, in pursuit to the cooperative learning STAD techniques, the student learning was assigned in team and was characterized of peer assistance where individual student showed his/her performance. The students were required to take the exam so that scores obtained would be further employed to determine the individual group's progress. In doing so, following steps were administrated. [2][3][4][5]

- Steps 1 Class Presentation - initially, content and teaching materials is introduced to students by which an instructor presents the WBI content through appropriate lessons.

- Step 2 Team Study - following the step 1, group activity is carried out by which students are assigned to investigate the event card, activity card, or individual content. Team members consult each other to tackle the problems and correct the mistakes committed by team members. To achieve this, the cooperation of all team members is quite needed.

- Step 3 Test - All individual learners themselves take the exam with no peer assistance intervention. They all are expected to do it best.

- Step 4 Individual Improvement/Progress is reported and determined on the basis of the calculation of the individual member's scores. Basically, the individuals are different in scores on basic knowledge.

- Step 5 Team Recognition is given to any team whose scores are higher than criteria scores.

Internet technology brings forth a convenience and is widely used as a powerful presentation tool that produces learning activities, particularly communication activity. As Passkorn stated the internet technology and Web-Based Instruction below, [6][7][8][9] 


\section{Web-based Instruction (WBI)}

Web Text involves presenting a content that primarily emphasizes messages or texts. Presentation is manipulated rapidly just little bit time on data transferring. Web text is ideal for presentation of the teaching plan, explaining the objectives, sequence of learning, content and evaluation. The descriptive content presentation covers the cognitive and affective learning objectives.

Web Graphic is a format of a presentation that focuses graphics and pictures. Presentation is somewhat slow because it takes longer time in transferring data. It's however ideal for content presentation where processes are illustrated explicitly, for examples, surgical or swimming procedure. The content presentation covers the psychomotor domain learning objectives.

Flash Animation is a format of a presentation that focuses the graphic animation and graphic moving pictures. Presentation is somewhat slow because it takes longer time in transferring data until completed. However, once downloading is finished, the animated graphic presentation work rapidly. It is idea for content presentation where processes are illustrated explicitly, for examples, surgical or swimming procedure. Like web graphic, content presentation covers the psychomotor domain learning objectives.

Streaming Video is a format of a presentation that focuses the animated graphics. Like flash animation, the streaming video is ideal for presentation where processes are illustrated explicitly and the content covers psychomotor domain learning objectives like flash animation and web graphic.

\section{Communication Activity}

Chat is a 2-way interactive interface in messaging format. This kind of communication is ideal for those instructors and learners who are synchronous in time, provided that the parties shall make an appointed time in advance for chatting. It is proper for giving consultation, giving answer to the doubted questions, giving additional explanation for unclear content.

Video Conference/Web Cam is a computer-mediated communication like chatting. More specifically, the parties can see each other. It is ideal for those instructors and learners, who are synchronous in time, provided that the parties shall make an appointed time for chatting through video conference or web cam. Advantageously, it is proper for giving consultation, giving answer to the doubted questions, giving additional explanation for unclear content in more efficiently way as it allows the parties to view each other as if they are at same place or classroom.

E-mail is another computer-mediated communication in which instructor and learner can e-mail the document each other asynchronously. In addition, the instructor can email all learners simultaneously and the learners can access to email at any time and respond it instantly. E-mail application is ideal for giving the answers to the doubted questions occurred in the traditional classroom, informing about teaching and learning news, handling homework assignment. However, this kind of communication remains privacy between instructor and learner.

Webboard is a computer-mediated communication where the instructor and learner interacts each other by leaving the messages on the webboard. In addition, the instructor can pose the topics as student homework and the students can reply for their assignment. Like e-email, webboard is an asynchronous communication activity.

As mentioned above, the teaching materials and communication activity can be effectively applied with the learning and teaching theories in the different formats, especially Cooperative Learning STAD technique. Hence, to solve the learning and teaching problems mentioned above, this study examined the application of the Cooperative Learning STAD to the lessons in the Applied Computer Programming for Education course.

\section{Research Objective}

1. To examine the application of the Cooperative Learning STAD technique to the lessons in the Applied Computer Programming for Education course.

2. To explore the student's opinion toward the application of the Cooperative Learning STAD technique to the Web-Based Instruction in the Applied Computer Programming for Education course.

\section{Population}

In this study, the samples included fifty-seven (26 female and 31 male) Master students in Computer Education Program, 
enrolled in the semester $1 / 2011$.

\section{Scope}

This study examined the application of the Cooperative Learning STAD technique to the Web-Based Instruction in Applied Computer Programming for Education course. The topics and methods to be examined including;

1. Methods - based on Cooperative Learning STAD technique [2][3][4][5]

- Step 1 Class Presentation

- Step 2 Team Study

- Step 3 Test

- Step 4 Individual Improvement

- Step 5 Team Recognition

2. Application of Fundamental Computer Program was a topic to be examined.

\section{Method ADDIE Model Process [10] [11]}

\subsection{Analyze}

1) Analyze condition and issues of learning and teaching for the Applied Computer Programming for Education

2) Explore theories related to the Cooperative Learning STAD technique

3) Examine type of teaching materials and Web-Based Instruction

7.2 Design

4) Instructional design by applying the Cooperative Learning STAD to teaching materials and Web-Based Instruction.

\subsection{Develop}

5) Develop lesson and web-based activities

\subsection{Implement}

6) Carry out learning and teaching activities through the application of the collaborative learning technique and Group Investigation (GI), and teaching materials and web-base learning activities

\subsection{Evaluate}

7) Evaluation - pre and post test

Testing was performed before learning, conducting web-based activities, report, and classroom discussion, and then post-test was performed.

8) Analyze data and summarize

9) Presentation was made to the Faculty of Education, and revision was made as advised by the Commissions.

10) Publicize in journals or academic meeting

\section{Result}

1. General information - participants included fifty-seven (26 female and 31 male) Master students in Computer Education Program, enrolled in the semester 1/2011.

2. Achievement on the application of the Cooperative Learning STAD to teaching materials and Web-Based Instruction for the Applied Computer Programming for Education course. 
Table 1: Comparison on Learning Achievement

\begin{tabular}{|c|c|c|c|c|c|}
\hline Evaluation & N & $\mathrm{X}_{-}^{-}$ & $\sum \mathrm{D}$ & $\sum \mathrm{D} 2$ & $\mathbf{T}$ \\
\hline Pre-Learning & 57 & 0.961538 & \multirow{2}{*}{428} & \multirow{2}{*}{3654} & \multirow{2}{*}{$54.8170^{\star *}$} \\
\hline Post-Learning & 57 & 9.192308 & & & \\
\hline
\end{tabular}

** T-value shows statistically significant at 0.05 (critical value of $t$ at $.05, \mathrm{df}=1.6883$ )

3. Effectiveness of teaching materials for the Applied Computer Programming for Education

Table 2: Effectiveness of Web-based Instructions

\begin{tabular}{|c|c|c|c|c|}
\hline $\begin{array}{c}\text { Effectiveness } \\
\text { of Teaching Materials }\end{array}$ & E1 & E1 & E1 & E2 \\
\hline & 90.24 & 89.51 & 90.73 & \multirow{2}{*}{92.76} \\
\hline E1 & \multicolumn{3}{|c|}{90.16} & \\
\hline
\end{tabular}

4. Students' Opinion

Table 3: Students' Opinion toward the Application of Cooperative Learning STAD To Web-Based Instruction

\begin{tabular}{|c|l|c|c|}
\hline No & Opinion & $\mathbf{X}^{-}$ & SD \\
\hline & Knowledge & 1.34 & 0.48 \\
\hline 1. & $\begin{array}{l}\text { Prior knowledge before studying the Applied Computer Programming for } \\
\text { Education }\end{array}$ & 4.80 & 0.40 \\
\hline 2. & $\begin{array}{l}\text { Acquired knowledge after studying the Applied Computer Programming for } \\
\text { Education }\end{array}$ & & \\
\hline & Cooperative Learning STAD Technique & 4.54 & 0.64 \\
\hline 3. & $\begin{array}{l}\text { Satisfaction with pedagogical arrangement on Cooperative Learning STAD } \\
\text { Technique }\end{array}$ & 4.61 & 0.59 \\
\hline 4. & Procedural clarity in Cooperative Learning STAD Technique & 4.66 & 0.57 \\
\hline 5. & $\begin{array}{l}\text { Cooperative Learning STAD procedures give the students an opportunity to } \\
\text { interexchange knowledge }\end{array}$ & 4.54 & 0.60 \\
\hline 6 & $\begin{array}{l}\text { Cooperative Learning STAD procedures give the students an opportunity to } \\
\text { assist each other }\end{array}$ & 4.59 & \\
\hline & Mean & & \\
\hline 7. & Seaching Materials and WBI Facilities & 4.68 & 0.57 \\
\hline 8. & Sufficiency of Web-Based Instruction data & 4.56 & 0.63 \\
\hline 9. & Accuracy and clearness of Web-Based Instruction & 4.71 & 0.51 \\
\hline 10. & $\begin{array}{l}\text { Convenience in access to the internet and Web-based Instruction, for } \\
\text { examples, Webboard, Mail, Search Engine Facebook }\end{array}$ & 4.54 & 0.64 \\
\hline 11. & Adequateness of computers for WBI schooling arrangement & 4.46 & 0.74 \\
\hline & Mean & 4.59 & \\
\hline
\end{tabular}

\section{Conclusion}

\subsection{General - fifty-seven participants (26 female and 31 male)}

\subsection{Effectiveness of Web-Based Instruction}

As shown in Table 2, the effectiveness of teaching materials and Web-Based Instruction, E1 and E2 $=90.16 / 92.76$, indicating that Web-Based Instruction was more efficient than criteria 85/85.

9.3 Students' opinion toward the application of the Cooperative Learning STAD technique to the Web-Based Instruction could be recognized in three areas, including knowledge, Cooperative Learning STAD, and materials teaching and 


\section{WBI facilities.}

Knowledge -the students reported that they possessed a slight knowledge on Application of Fundamental Computer Program pre-learning $\left(x_{,}^{-}=1.34\right)$ and possessed most knowledge pre-learning $\left(x_{,}^{-}=4.80\right)$.

Cooperative Learning STAD - the students' opinion was averaged highest $\left(x^{-}=4.59\right)$ for opportunity of interexchange of knowledge, procedural clarity in Cooperative Learning STAD, Cooperative Learning STAD procedures give the students an opportunity to assist each other, and students reported utmost satisfaction with Cooperative Learning STAD techniques ( $x_{-}^{-}=4.66,4.61,4.54,4.54$, respectively)

Teaching Materials and WBI Facilities - students' opinion was averaged highest $\left(x_{,}^{-}=4.59\right)$ for accuracy and clearness of the Web-based Instruction, satisfaction with application of Web-Based Instruction, sufficiency of Web-Based Instruction data, Convenience in access to the internet and Web-based Instruction for examples, Webboard, Mail, Search Engine Facebook ( $x^{-}=4.71,4.68,4.56,4.54$, respectively)

\section{Discussion}

The procedures in the Cooperative Learning STAD could be discussed as follows.

- Steps 1 Class Presentation - the classroom instructor's personality appeared consistent with the requirement of those Thai students who desire to learn with the actual instructor for the first meeting at the initial learning and teaching process.

- Step 2 Team Study - At this stage, the Web-based Instruction is carried out by the researcher and allows the peer assistance that gives the opportunity for those higher performance students to transfer their knowledge to peers. In addition, it found that peer assistance enhances more learning performance than self-learning.

- Step 3 Test - At this stage, the student are more eager to take the test so that they can know what the extent of their group performance will be as compared to other groups. The students in this stage put the significance on themselves in the way that they may lower the group scores, so they are more likely to be diligent.

- Step 4 Individual Improvement/Progress - the students give more attention to hear the group improvement scores. The students are interested to know which level of scores they obtain. If individual's score is low, it results in the low group scores.

- Step 5 Team Recognition - the students are so happy being told of their highest individual improvement scores. The students with low improvement scores will make an effort to make a correction to improve the group scores, especially those students with frequent absenteeism; they try to attend the class regularly and on-time so that they can join the cooperative learning activities.

\section{Suggestions}

1. The Cooperative Learning should be applied with the Web-based Instruction for Application of Fundamental Computer Program course in other different techniques, for examples, Jigsaw, TGT, etc.

2. The Cooperative Learning should be applied with the Web-based Instruction for other courses, particularly workshop-focusing courses.

\section{References}

E-Register Naresuan University. Academic Results. [Online] from http://www.reg.nu.ac.th/registrar/student.asp?avs979989363=17 Collaborative Learning. '44 Benefits of Collaborative Learning'. Online Source: http://www.gdrc.org/kmgmt/c-learn/44.html. 1 June 2011 Collaboration - Wikipedia, the free encyclopedia. 'Collaboration Learning'. [Online] Source: http://en.wikipedia.org/wiki/Collaboration. Thisana Khammanee, 'Teaching Sciences', Bangkok; Thai Wattanapanich 1999.

Collaborative Learning Techniques Workshop Handouts. 'Collaborative Learning Techniques' [Online] Source: http://www.uwlax.edu. [1 June 2011]

Passkorn Ruengrong, 'Research on Collaborative Learning Model - Jigsaw Technique', the National Conference on Computer Information Technologies 2009 (CIT2009) during January 15, 2009 - February 14, 2009.

Passkorn Ruengrong, 'An Application of Collaborative learning techniques, Group Investigation (GI), with teaching materials on internet network course Logical Thinking', the The Asian Conference on Technology in the Classroom (ACTC2011) during June 10-12, 2011.

Passkorn Ruengrong, 'Study of the Appropriateness of Teaching Materials and Web- based Activity Presentation - STAD Collaborative 
Learning Technique, the Academic Conference: Visual Technologies Relations No.1 December 11-12, 2008, Silpakorn University,2008.

Passkorn Ruengrong, 'Article on the Application of WBI lesson and STAD Collaborative Learning Technique, Journal of Education, Faculty of Education, Naresaun University 2009.

ADDIE Model - Wikipedia, the free encyclopedia. 'ADDIE Model'. [Online] Source: http://en.wikipedia.org/wiki/ADDIE_Model [2 June 2011]

Tools for Design and Development of Online Instruction. 'The ADDIE Model'. [Online] Source: http://www.aect.org/edtech/edition3 /ER5849x_C050.fm.pdf. [3 June 2011] 